\title{
Pemanfaatan Hasil Tangkap Ikan melalui Pelatihan Pembuatan Pempek di Kampung Rempang Cate
}

\author{
Oktavianto Gustin, Arif Roziqin, Sudra Irawan, Luthfiya Ratna Sari, Muhammad \\ Zainuddin Lubis, Wenang Anurogo, Uuf Brajawidagda, Metta Santiputri, Nur Cahyono \\ Kushardianto, Nur Zahrati Janah, Mir'atul Khusna Mufida, Yeni Rokhayati, Ari \\ Wibowo, Satriya Bayu Aji, Fandy Neta, Rizki Widi Pratama, Anis Rahmi, Dwiki Novri \\ Ditya, Rivki Ryan Nugraha.
}

Jurusan Teknik Informatika, Politeknik Negeri Batam, Jalan Ahmad Yani, 29461, Kota Batam, Indonesia

\begin{abstract}
The number of tourists and the fame of a long sand beach is still lacking, therefore it is necessary to introduce to the public about the beauty and marine products that are owned on Pasir Panjang beaches. This service community was carried out to socialize the benefits of marine products through training in making Pempek in the Pasir Panjang Coastal Village.

We have carried out this service with the Partner of RW. 03 Pasir Panjang, Pasir Panjang Village, Rempang Cate District on Friday, July 27, 2018. The questionnaire results of Speaker questionnaire, equipment and Room with a Likert Scale were found that the interpretation score from all observation was all worth $100 \%$ and include in the interval category very well, which meant that it was rated very well by 18 respondents. While for the consumption questionnaire the interpretation of the score of the observations is worth $95.556 \%$ and is included in the interval category Very Well which means it is rated very well by 18 Respondents. The results of monitoring on October 22, 2018 were obtained information that there were residents who had made Pempek and sold in Pasir Panjang environments, while production and sales had stopped due to constraints Limited fishing results. The results of the questionnaire obtained the most suggestions for further training to hold Crafts, other input so that the training activities continued. The results of the questionnaire obtained the most suggestions for further training is handicraft, other input so that the training activities continued.
\end{abstract}

Keyword — Fish Catch; Making Pempek, Likert Scale, Rempang Cate.

Abstrak- Jumlah wisatawan dan kemahsyuran pantai pasir panjang hingga saat ini masih dirasa kurang, oleh karena itu perlu di kenalkan ke masyarakat luas tentang keindahan dan hasil laut yang dimiliki di pantai pasir panjang. Pengabdian ini dilakukan untuk sosialisasi manfaat hasil laut melalui Pelatihan pembuatan Pempek di Kampung Pesisir Pasir Panjang.

Pengabdian ini telah kami laksanakan dengan Mitra RW. 03 Pasir Panjang Kelurahan Pasir Panjang Kecamatan Rempang Cate pada Hari Jumat tanggal 27 Juli 2018. Hasil Kuesioner Pemateri, Peralatan dan Ruangan dengan pengukuran Skala Likert didapatkan bahwa interpretasi skor hasil pengamatan semuanya bernilai $\mathbf{1 0 0 \%}$ dan masuk dalam kategori interval Sangat Baik yang berarti dinilai sangat Baik oleh 18 Responden. Sedangkan untuk kuesioner konsumsi interpretasi skor hasil pengamatan bernilai $95,556 \%$ dan masuk dalam kategori interval Sangat Baik yang berarti dinilai sangat Baik oleh 18 Responden. Hasil monitoring pada tanggal 22 Oktober 2018 didapatkan informasi bahwa terdapat warga yang telah membuat pempek dan berjualan di lingkungan pasir panjang, sedangkan produksi dan penjualan sempat berhenti karena terkendala Hasil tangkap ikan yang terbatas. Hasil kuesioner didapatkan saran terbanyak untuk selanjutnya agar diadakan pelatihan adalah Kerajinan tangan, masukan lainnya agar kegiatan pelatihan berlanjut.

Kata Kunci-Hasil Tangkap Ikan, Pembuatan Pempek, Skala Likert, Rempang Cate. 


\section{PENDAhUluan}

Batam merupakan termasuk salah satu kota yang memiliki perkembangan sangat pesat diantara kota-kota di Indonesia dengan kebutuhan lahan industri, pemukiman dan perdagangan yang besar (Gustin et al., 2017; Gustin et al., 2018), karena kebutuhan lahan cukup besar yang menyebabkan vegetasi/tumbuhan berkurang bisa diperkirakan meningkatkan suhu permukaan Tanah meningkat (Gustin et al., 2013). Selain terkenal sebagai Kota Industri karena berdekatan berbatasan langsung dengan Negara Singapura dan Malaysia, Batam juga sering dikunjungi oleh wisatawan mancanegara maupun lokal karena memiliki banyak obyek wisata salah satunya pantai dengan panjang pantai dan keelokan bahari yang menarik. Selain keindahan yang menarik wisatawan, Batam juga memiliki hasil laut yang berlimpah. Pemandangan yang indah Pulau Batam tersebut didukung oleh perbukitan-perbukitan kecil yang berada di daerah pesisir (Roziqin et al., 2018).

Kampung Pesisir Pasir Panjang terletak di Kelurahan Pasir Panjang Kecamatan Rempang Cate Kota Batam terletak satu setengah jam atau sekitar $60 \mathrm{Km}$ dari Pusat Kota Batam juga memiliki keindahan pantai dan hasil laut yang berlimpah. Gambar 1 menunjukkan Lokasi Kampung Pesisir Pasir Panjang dengan hamparan panjang pantai sekitar 4.000 M.

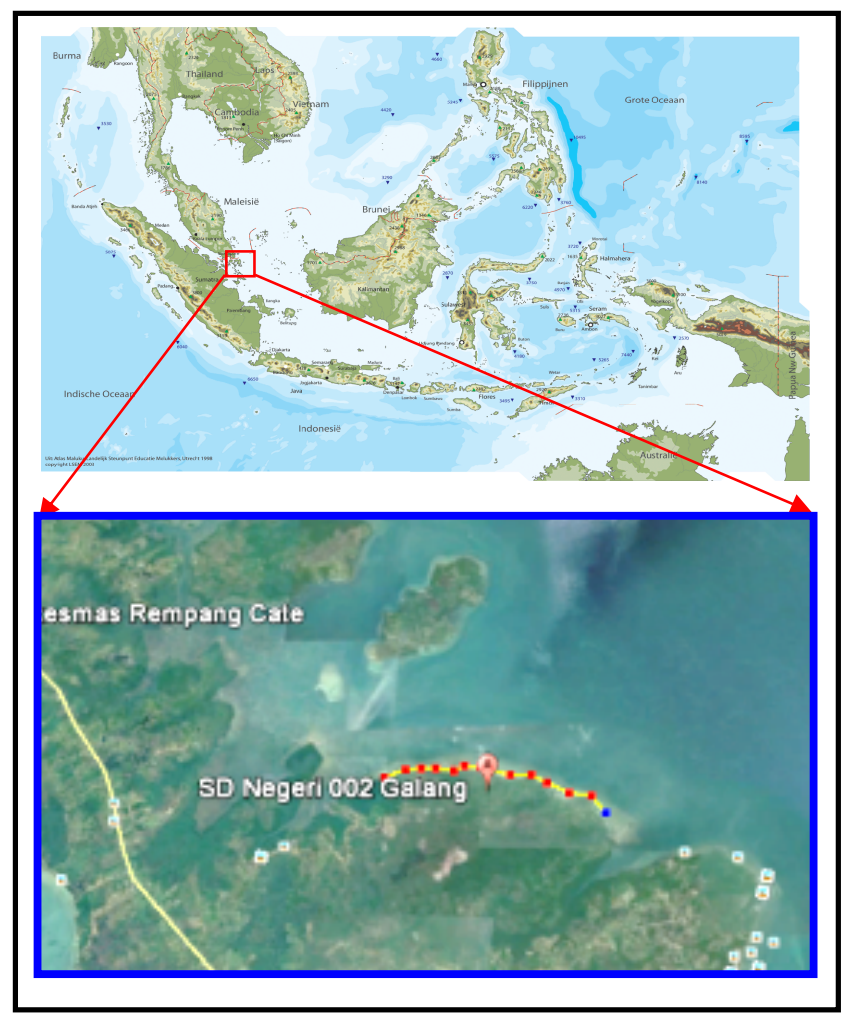

Gambar 1. Lokasi Pesisir Pantai Pasir Panjang. 
Jumlah wisatawan dan kemahsyuran pantai pasir panjang hingga saat ini masih dirasa kurang, untuk itu perlu di kenalkan ke masyarakat luas tentang keindahan dan hasil laut yang dimiliki di pantai pasir panjang. Hal ini telah dibuktikan dengan hasil kunjungan Tim Politeknik Negeri Batam (Polibatam) beberapa waktu lalu.

Dari hasil survei didapati garis pantai yang cukup panjang dan karakteristik pantai yang potensial untuk pariwisata, sehingga cocok untuk dijadikan sebagai daerah objek wisata seperti Gambar 2.

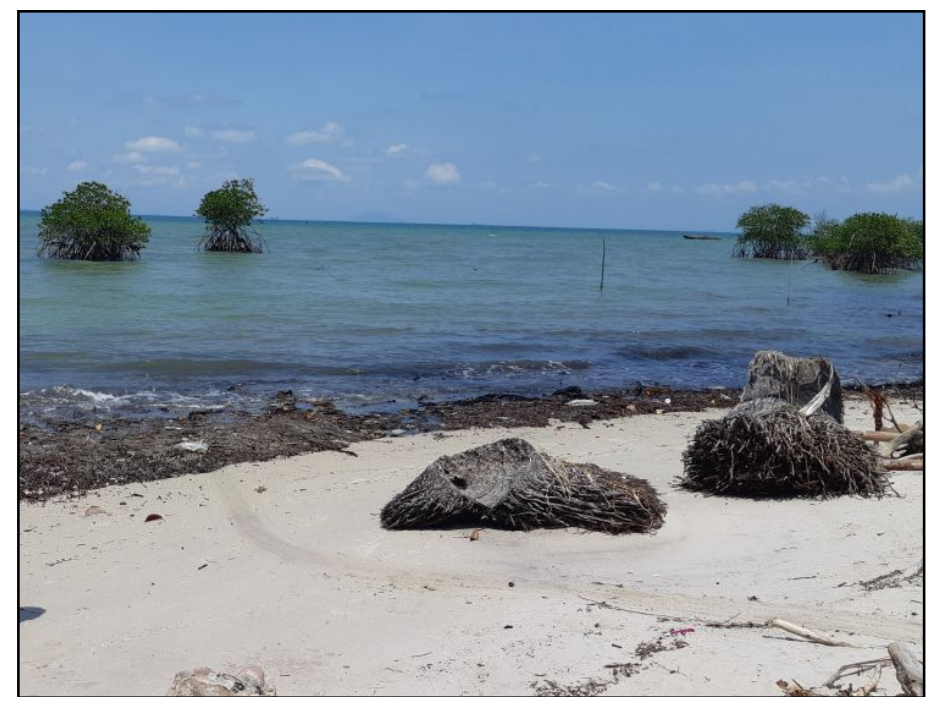

Gambar 2. Pesisir Pantai Pasir Panjang.

Dari hasil kunjungan Tim Polibatam, keterbatasan keahlian masyarakat kampung pasir panjang masih dirasa kurang untuk pengetahuan mengolah hasil laut dan kemanfaatan hasil laut, oleh karena itu kami melakukan pengabdian kepada masyarakat mengenai "Pemanfaatan Hasil Tangkap Ikan melalui Pelatihan Pembuatan Pempek di Kampung Rempang Cate”. Harapannya dengan melalui pelatihan dapat mengembangkan sumberdaya manusia (Afiatin et al., 2013) dan Produk unggulan hasil pengabdian melalui pelatihan di daerah Kampung Pasir Panjang dapat menambah nilai Ekonomi hasil tangkapan ikan, memberdayakan masyarakat sekitar, menarik investor hingga menarik kunjungan wisatawan lokal bahkan mancanegara.

Permasalahan mitra pada pengabdian ini adalah pengetahuan kemanfaatan dan keahlian dalam proses pengolahan hasil laut bagi masyarakat Kampung Pesisir Pantai Pasir Panjang. Atas dasar Pendahuluan dan permasalahan yang telah diuraikan sebelumnya, maka terdapat permasalahan yang akan dijadikan dasar dan fokus untuk dikaji lebih lanjut pada pengabdian ini, yaitu:

- Kemanfaatan hasil laut belum sepenuhnya diketahui oleh semua masyarakat, terutama yang berlokasi di wilayah Kampung Pesisir Pasir Panjang. 
- Salah satu contoh kemanfaatan hasil laut seperti proses pembuatan Pempek belum diketahui oleh masyarakat Kampung Pesisir Pasir Panjang.

- Perlunya evaluasi program pengabdian melalui hasil kuesioner Pemateri, Peralatan, Ruangan dan Konsumsi dengan pengukuran Skala Likert oleh Responden atau peserta yang mengikuti pelatihan.

\section{TINJAUAN PUSTAKA}

Indonesia adalah negara maritim yang memiliki luas laut yang sangat luas. Luas laut wilayah Indonesia hampir seluruhnya adalah perairan, sehingga Indonesia dikatakan sebagai negara maritim yang terdiri dari pulau-pulau kecil maupun besar. Sumberdaya alam yang melimpah di perairan Indonesia dengan banyaknya hewan dan biota laut Indonesia yang tersebar di seluruh laut Indonesia (Gustin, 2016). Kepulauan Riau adalah salah satu Provinsi yang ada di Indonesia yang memiliki perairan laut yang lebih luas dibandingkan wilayah daratan.

Provinsi Kepulauan Riau merupakan Provinsi ke-32 di Indonesia yang dibentuk melalui Undang-undang Nomor 25 tahun 2002. Provinsi Kepulau Riau berbatasan langsung dengan beberapa negara tetangga. Batas-batas wilayah Provinsi Kepulaun Riau adalah sebagai berikut:

- Sebelah Utara : Vietnam dan Kamboja.

- Sebelah Selatan: Provinsi kepulauan Bangka Belitung dan Jambi.

- $\quad$ Sebelah Barat: Singapura, Malaysia dan Provinsi Riau

- $\quad$ Sebelah Timur: Malaysia, Brunei, dan Provinsi Kalimantan Barat.

Lokasi Provinsi Kepulauan Riau dapat dilihat pada Gambar 4.

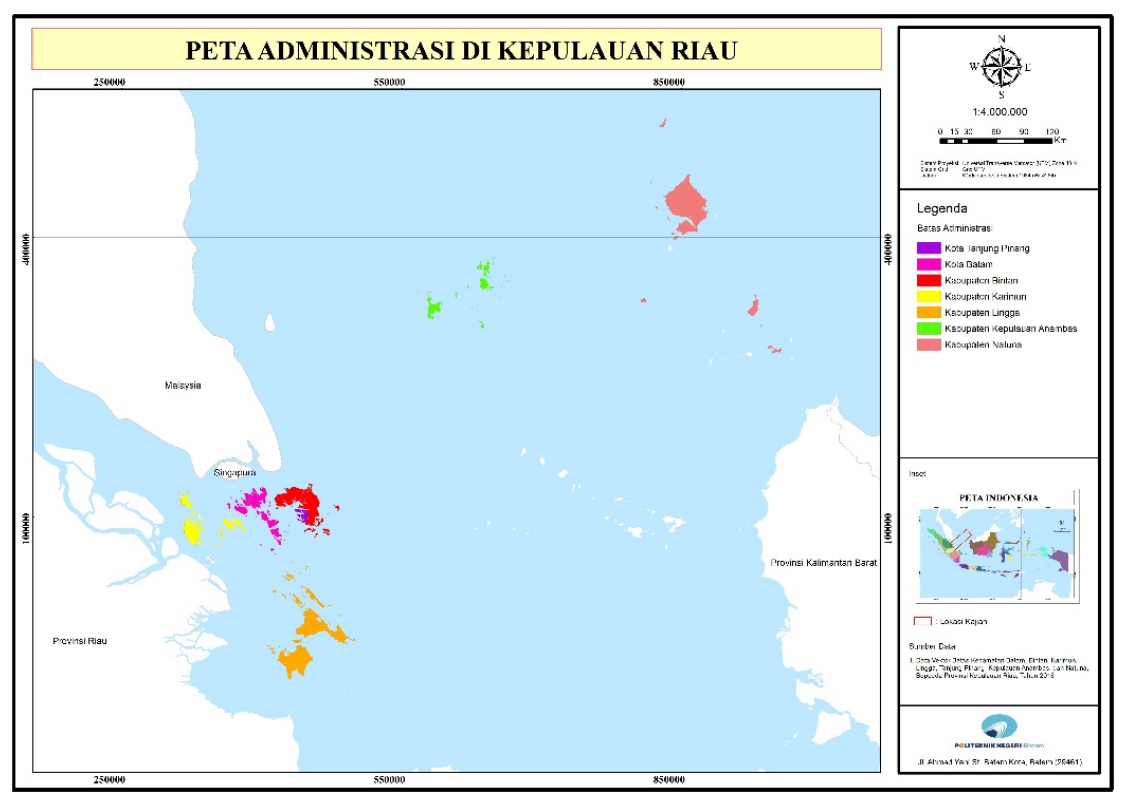

Gambar 3. Lokasi Provinsi Kepulauan Riau. 
Berdasarkan pada Gambar 3, menunjukkan bahwa Provinsi Kepulauan Riau memiliki potensi luas laut yang sangat besar. Keberadaan luas laut yang sangat besar juga diiringi dengan potensi sumberdaya ikan yang sangat besar. Secara garis besar permasalahan di Provinsi Kepulauan Riau dapat dijelaskan dalam analisis lingkungan strategis yang tercakup dalam faktor internal (kekuatan dan kelemahan) dan faktor eksternal (peluang dan tantangan) dalam RPJMD Provinsi Kepulau Riau 2016 - 2021 (Pemprov Kepri, 2016).

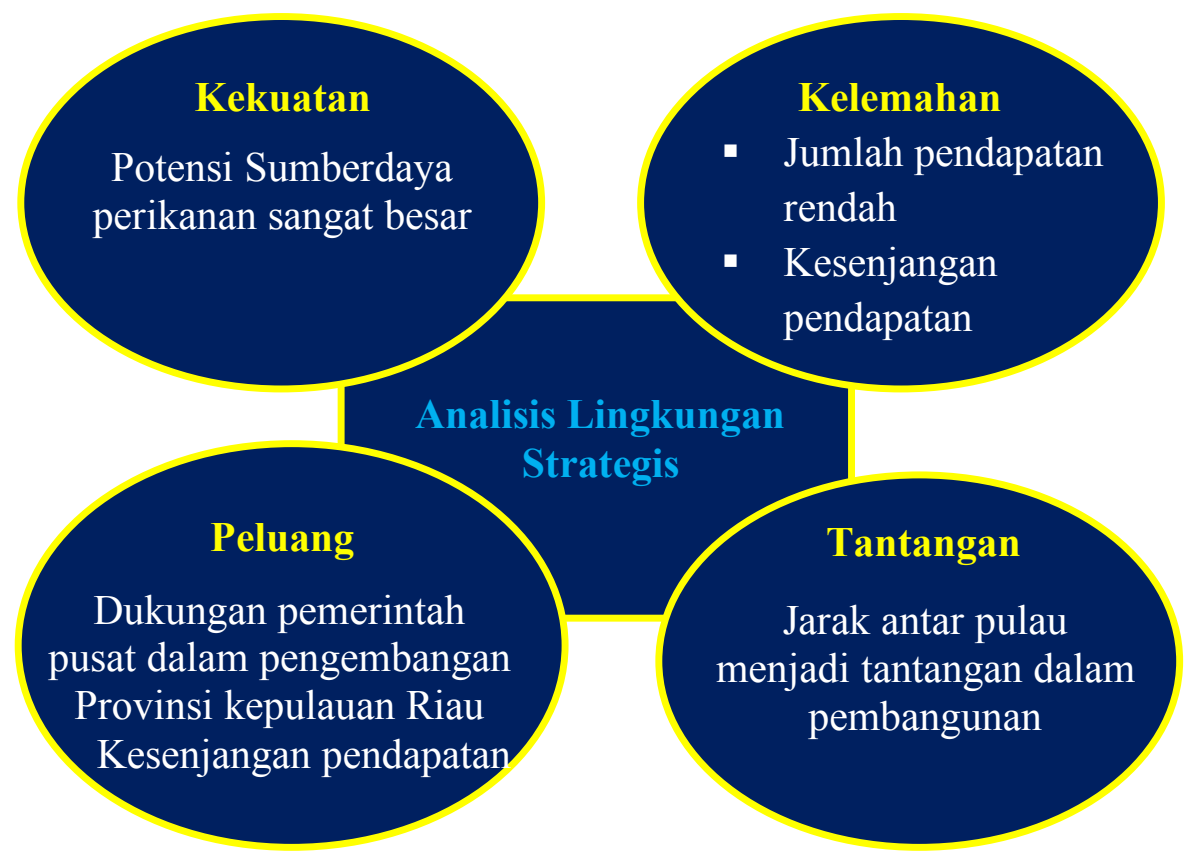

Gambar 4. Analisis Lingkungan Strategis.

Berdasarkan analisis lingkungan strategis yang tertuang pada RPJMD seperti pada Gambar 4, menunjukkan bahwa Provinsi Kepulauan Riau memiliki sejumlah potensi besar yang dapat dimanfaatkan untuk meningkatkan pendapatan dan kesejahteraan masyarakatnya. Salah satu sumber potensi yang dapat dimanfaatkan adalah melalui potensi perikanan di laut. Potensi perikanan di laut diharapkan dapat lebih dioptimalkan dengan melakukan pengolahan lebih lanjut agar hasil perikanan laut memiliki nilai tambah.

Pengolahan yang dapat dilakukan untuk memberikan nilai tambah dengan menjadi ikan sebagai bahan dasar untuk bahan makanan Pempek. Pempek adalah makanan tradisional Palembang, yang dibuat dari adonan daging ikan cincang atau giling, tepung/sagu, dan bumbu, kemudian direbus (Bnpbpadang, 2016). Sumberdaya ikan yang melimpah di Kepulauan Riau termasuk di daerah pesisir pasir panjang dapat dimanfaatkan untuk diolah menjadi Pempek. Pengolahan ikan di pesisir pasir panjang dapat memberikan cita rasa yang berbeda sehingga hasil olahan Pempeknya ala pasir panjang Kepulauan Riau. 
Evaluasi Program Pengabdian ini diukur menggunakan skala Likert, Likert merupakan skala yang memiliki empat atau lebih butir pertanyaan sehingga membentuk sebuah skor/nilai yang mempresentasikan sikap, pendapat dan persepsi seseorang atau kelompok orang tentang kejadian atau gejala sosial (Likert, 1932).

\section{METODE}

Kegiatan Pengabdian yang kami rencanakan mempunyai program berkelanjutan sehingga diharapkan bermanfaat dan berdampak luas khususnya bagi Desa Binaan Politeknik ini. Program berkelanjutan seperti ditampilkan pada Gambar 5 berikut.

Sosialisasi Manfaat Hasil Laut,

Pelatihan Pembuatan Pempek

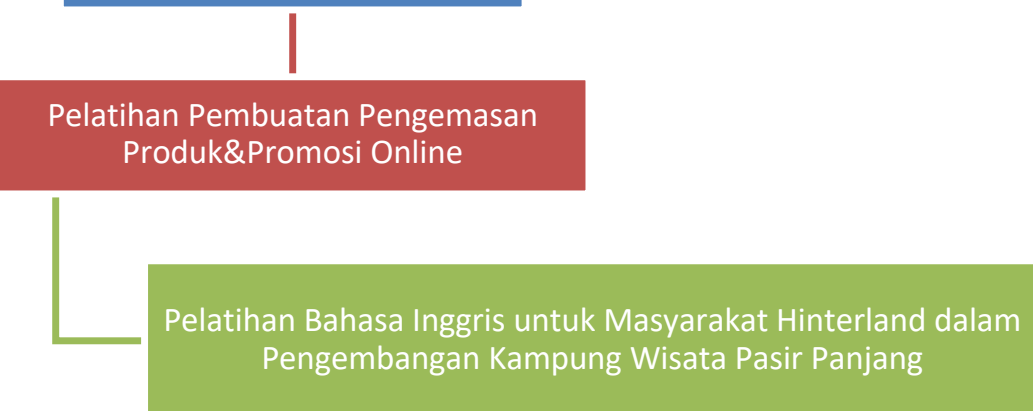

Gambar 5. Program Pengabdian Pembinaan Desa Berkelanjutan.

Metode pelaksanaan pada pengabdian yang diajukan yaitu dengan membagi kegiatan kepada masyarakat menjadi tiga tahapan. Tahapan persipan, pelaksanaan, dan monitoring seperti pada Gambar No. 6.

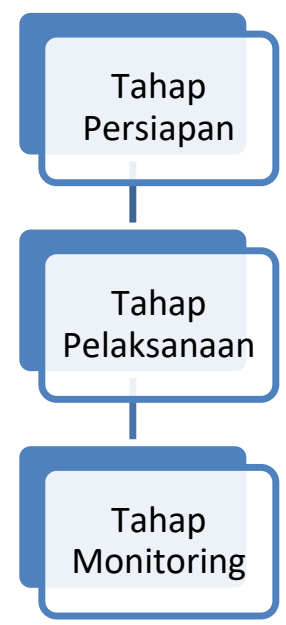

Gambar 6. Diagram Alir Pengabdian. 


\subsection{Tahap Persiapan}

Tahap persiapan ini meliputi survei pendahuluan, peninjauan lokasi, komunikasi dengan perwakilan warga, persiapan mencari pemateri, mengumpulkan perlengkapan, bahan dan peralatan untuk pelaksanaan pengabdian masyarakat. Persiapan bahan seperti ikan giling, tepung terigu, sagu, garam, bawang putih, air. Peralatan meliputi alat penggorengan seperti wajan atau penggorengan dan kompor.

\subsection{Tahap Pelaksanaan}

Tahap pelaksanaan dilakukan di lokasi pengabdian di daerah Pasir Panjang RW. 3 Kelurahan Pasir Panjang, Kecamatan Rempang Cate, Kota Batam, Provinsi Kepulauan Riau dengan Sosialisasi pemanfaatan hasil laut, pelatihan pengolahan ikan untuk dijadikan olahan makanan pempek ala pasir panjang oleh Trainer.

\subsection{Tahap Monitoring}

Pelaksanan kegiatan pengabdian masyarakat yang telah dilaksanakan perlu dilakukan monitoring secara berkala. Monitoring yang dilakukan dalam bentuk perkembangan tindak lanjut hasil pelatihan, peningkatan keahlian untuk menghasilkan aneka macam pempek, dan strategi pemasaran produk.

\section{IV.HASIL DAN PEMBAHASAN}

\subsection{Hasil Kegiatan}

Kegiatan pengabdian ini telah kami laksanakan pada hari Jumat 27 Juli 2018 bertempat di Kampung Pasir Panjang Kelurahan Pasir Panjang Kecamatan Rempang Cate dimulai Pukul 09.30-14.00 WIB. Dengan mendatangkan 3 Trainer dan dihadiri oleh 17 Peserta, Perangkat RT. 01, 02 RW. 3 Kelurahan Pasir Panjang Kecamatan Rempang Cate. Peserta pelatihan menyatakan sangat terbantu dengan adanya pelatihan ini. Pelaksana pengabdian juga memberi Cindera mata berupa 2 Unit Penggiling Daging untuk membantu Masyarakat dalam mengolah Daging ikan agar lebih mudah.

\subsection{Evaluasi Program}

Setelah pelaksanaan pelatihan pembuatan pempek, panitia meng-Evaluasi Program Pengabdian yang diukur menggunakan skala Likert melalui kuesioner 5 rentang nilai dengan angka 5 sebagai nilai tertinggi (sangat baik) dan 1 sebagai nilai terendah (Sangat tidak baik) yang di bagi ke 18 Responden, sedangkan penliaiannya sebagai berikut: 
- Pemateri
a. Penguasaan materi
b. Metode Penyampaian
c. Kualitas Materi
d. Ketanggapan Tim Melayani (Pertanyaan dll)

- Fasilitas Pendukung
a. Peralatan
b. Ruangan
c. Konsumsi

Berikut kriteria interpretasi skornya berdasarkan interval:

Angka 0\% - 19,99\% = Sangat (tidak setuju/buruk/kurang sekali)

Angka 20\% - 39,99\% = Tidak setuju / Kurang baik

Angka 40\%-59,99\% = Cukup / Netral

Angka $60 \%-79,99 \%=$ Setuju/Baik/suka

Angka $80 \%-100 \% \quad=$ Sangat $($ setuju/Baik/Suka)

Dari kuesioner yang disebarkan pada kegiatan pelatihan didapatkan:

a. Jumlah Responden $=18$ Orang

b. Skor Tertinggi $=$ rentang nilai tertinggi $\mathrm{x}$ Jumlah Responden $=5 \times 18=90$

c. Skor Terendah $=$ rentang nilai terendah $\mathrm{x}$ Jumlah $8=1 \times 18=18$

\subsubsection{Hasil Kuesioner Pemateri}

Setelah hasil kuesioner Pemateri direkap didapatkan hasil sebagai berikut:

a. Penguasaan Materi

i. Skor Rentang $5=5 \times$ jumlah responden yang memilih $=5 \times 18=90$

ii. Skor Rentang $4=4 \times$ jumlah responden yang memilih $=4 \times 0=0$

iii. Skor Rentang $3=3 \times$ jumlah responden yang memilih $=3 \times 0=0$

iv. Skor Rentang $2=2 \times$ jumlah responden yang memilih $=2 \times 0=0$

v. Skor Rentang $1=1 \mathrm{x}$ jumlah responden yang memilih $=1 \mathrm{x} 0=0$

vi. Total Skor $=90+0+0+0+0=90$

vii. Interpretasi skor hasil pengamatan $=$ Total Skor/Skor tertinggix $100 \%=$ $90 / 90 \times 100 \%=100 \%$

b. Metode Penyampaian

i. Skor Rentang $5=5 \times$ jumlah responden yang memilih $=5 \times 18=90$

ii. Skor Rentang $4=4 \times$ jumlah responden yang memilih $=4 \times 0=0$

iii. Skor Rentang $3=3 \times$ jumlah responden yang memilih $=3 \times 0=0$ 
iv. Skor Rentang $2=2 \times$ jumlah responden yang memilih $=2 \times 0=0$

v. Skor Rentang $1=1 \times$ jumlah responden yang memilih $=1 \times 0=0$

vi. Total Skor $=90+0+0+0+0=90$

vii. Interpretasi skor hasil pengamatan $=$ Total Skor/Skor tertinggix $100 \%=$ $90 / 90 \times 100 \%=100 \%$

c. Kualitas Materi

i. Skor Rentang $5=5 \times$ jumlah responden yang memilih $=5 \times 18=90$

ii. Skor Rentang $4=4 \mathrm{x}$ jumlah responden yang memilih $=4 \mathrm{x} 0=0$

iii. Skor Rentang $3=3 \times$ jumlah responden yang memilih $=3 \times 0=0$

iv. Skor Rentang $2=2 \times$ jumlah responden yang memilih $=2 \times 0=0$

v. Skor Rentang $1=1 \times$ jumlah responden yang memilih $=1 \times 0=0$

vi. Total Skor $=90+0+0+0+0=90$

vii. Interpretasi skor hasil pengamatan $=$ Total Skor/Skor tertinggix $100 \%=$ $90 / 90 \times 100 \%=100 \%$

d. Ketanggapan Tim Melayani (Pertanyaan dll)

i. Skor Rentang $5=5 \times$ jumlah responden yang memilih $=5 \times 18=90$

ii. Skor Rentang $4=4 \times$ jumlah responden yang memilih $=4 \times 0=0$

iii. Skor Rentang $3=3 \times$ jumlah responden yang memilih $=3 \times 0=0$

iv. Skor Rentang $2=2 \times$ jumlah responden yang memilih $=2 \times 0=0$

v. Skor Rentang $1=1 \times$ jumlah responden yang memilih $=1 \times 0=0$

vi. Total Skor $=90+0+0+0+0=90$

vii. Interpretasi skor hasil pengamatan $=$ Total Skor/Skor tertinggix $100 \%=$ $90 / 90 \times 100 \%=100 \%$

Dari hasil kuesioner pertanyaan untuk pemateri dan selanjutnya ditampilkan dalam diagram batang beserta kriteria interpretasi skornya berdasarkan interval dapat dilihat pada gambar 7 .

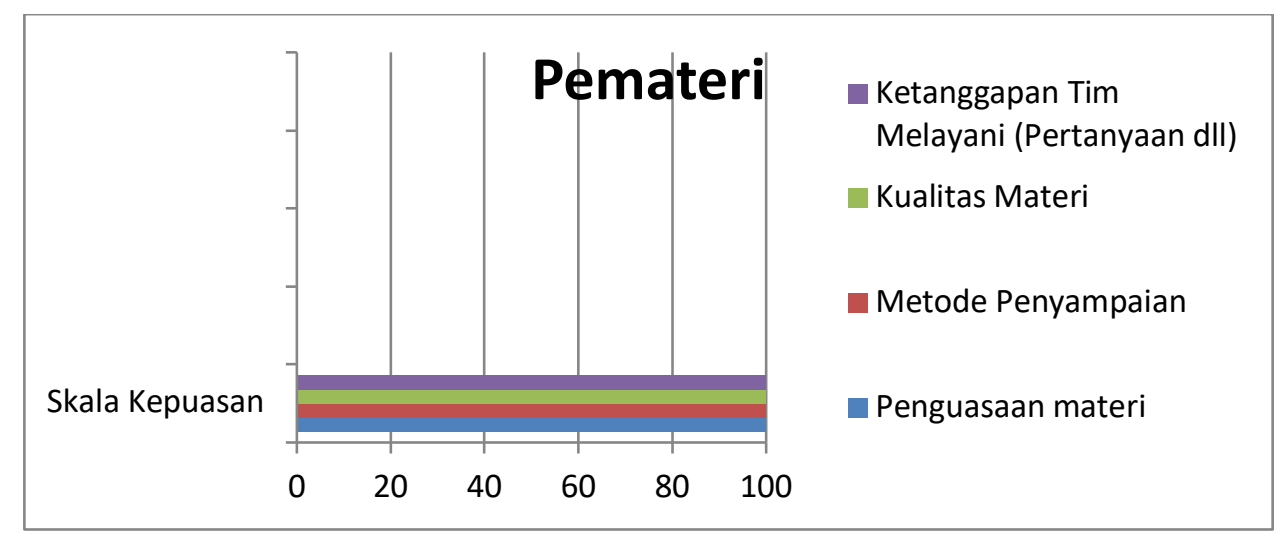

Gambar 7. Hasil Kuesioner Pemateri dalam Diagram Batang. 


\subsubsection{Hasil Kuesioner Fasilitas Pendukung}

Setelah hasil kuesioner Fasilitas Pendukung direkap didapatkan hasil sebagai berikut:

a. Peralatan

i. Skor Rentang $5=5 \times$ jumlah responden yang memilih $=5 \times 18=90$

ii. Skor Rentang $4=4 \times$ jumlah responden yang memilih $=4 \times 0=0$

iii. Skor Rentang $3=3 \times$ jumlah responden yang memilih $=3 \times 0=0$

iv. Skor Rentang $2=2 \times$ jumlah responden yang memilih $=2 \times 0=0$

v. Skor Rentang $1=1 \times$ jumlah responden yang memilih $=1 \times 0=0$

vi. $\quad$ Total Skor $=90+0+0+0+0=90$

vii. Interpretasi skor hasil pengamatan $=$ Total Skor/Skor tertinggix $100 \%=$ $90 / 90 \times 100 \%=100 \%$

b. Ruangan

i. Skor Rentang $5=5 \times$ jumlah responden yang memilih $=5 \times 18=90$

ii. Skor Rentang $4=4 \times$ jumlah responden yang memilih $=4 \times 0=0$

iii. Skor Rentang $3=3 \times$ jumlah responden yang memilih $=3 \times 0=0$

iv. Skor Rentang $2=2 \times$ jumlah responden yang memilih $=2 \times 0=0$

v. Skor Rentang $1=1 \mathrm{x}$ jumlah responden yang memilih $=1 \mathrm{x} 0=0$

vi. Total Skor $=90+0+0+0+0=90$

vii. Interpretasi skor hasil pengamatan $=$ Total Skor/Skor tertinggix $100 \%=$ $90 / 90 \times 100 \%=100 \%$

c. Konsumsi

i. Skor Rentang $5=5 \times$ jumlah responden yang memilih $=5 \times 14=70$

ii. Skor Rentang $4=4 \times$ jumlah responden yang memilih $=4 \times 4=16$

iii. Skor Rentang $3=3 \times$ jumlah responden yang memilih $=3 \times 0=0$

iv. Skor Rentang $2=2 \times$ jumlah responden yang memilih $=2 \times 0=0$

v. Skor Rentang $1=1 \times$ jumlah responden yang memilih $=1 \times 0=0$

vi. $\quad$ Total Skor $=70+16+0+0+0=86$

vii. Interpretasi skor hasil pengamatan $=$ Total Skor/Skor tertinggi $\mathrm{x} 100 \%=$ $86 / 90 \times 100 \%=95,556 \%$

Dari hasil kuesioner pertanyaan untuk faslitas pendukung dan selanjutnya ditampilkan dalam diagram batang beserta kriteria interpretasi skornya berdasarkan interval dapat dilihat pada gambar 8 . 


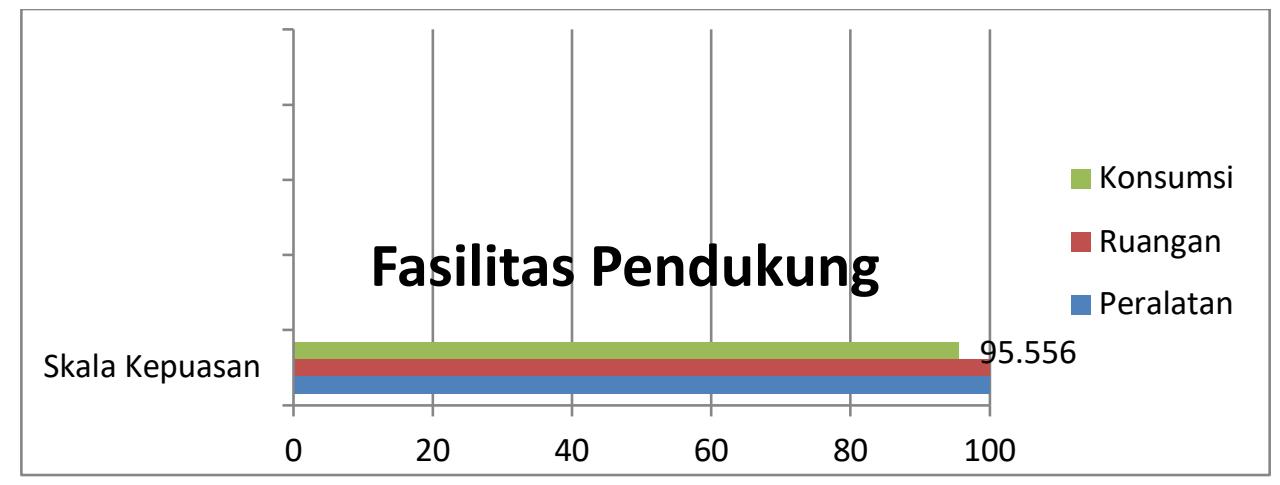

Gambar 8. Hasil Kuesioner Fasilitas Pendukung dalam Diagram Batang.

\subsubsection{Hasil Kuesioner Pertanyaan Uraian}

Untuk pertanyaan uraian pertama materi pelatihan lain yang ingin di ikuti terdapat beberapa jawaban sebagai berikut:

a. Kerajinan tangan: 9 Orang

b. Olahraga Voli: 1 Orang

c. Bercocok Tanam: 1 Orang

d. Syuting: 2 Orang

e. Olahraga: 1 Orang

4. Untuk Saran (masukan) terdapat jawaban sebagai berikut:

a. Kegiatan berlanjut: 10 Orang

b. Pelatihan Olahraga: 2 Orang

c. Pelatihan yang lain: 3 Orang

d. Saya belajar lebih giat lagi, terimakasih: 1 Orang

e. Pelatihan Olahraga Voli dan Senam: 1 Orang

\subsection{Monitoring}

Pada tanggal 22 Oktober 2018 Pelaksana telah melakukan monitoring ke lokasi dan sempat mewawancarai warga dan didapatkan informasi bahwa terdapat warga yang telah membuat pempek dan berjualan di lingkungan pasir panjang, hanya saja terkendala Hasil tangkap ikan yang terbatas.

\section{KESIMPULAN}

Berdasarkan Pelaksanaan Pengabdian yang telah dilakukan didapat beberapa kesimpulan yaitu:

a. Masyarakat pesisir Pantai Pasir Panjang mengetahui manfaat dari hasil budidaya laut disekitar 
pantai, dan masyarakat mampu mengolah hasil laut tersebut berupa pempek.

b. Membentuk masyarakat yang produktif, dan kemandirian masyarakat secara ekonomi atau nilai tambah ekonomi.

c. Peningkatan level keberdayaan mitra berupa pengetahuannya meningkat, keterampilannya meningkat, jumlah produknya meningkat, jenis produknya meningkat, kapasitas produksi meningkat, jumlah asset meningkat dan jumlah tenaga kerjanya meningkat.

d. Hasil untuk Penguasaan materi, metode penyampaian, kualitas materi dan ketanggapan tim melayani (pertanyaan dll.) dalam Kuesioner Pemateri didapatkan bahwa interpretasi skor hasil pengamatan semuanya bernilai $100 \%$ dan di gambar 7 masuk dalam interval Sangat Baik yang berarti Pemateri tersebut dinilai sangat Baik oleh 18 Responden.

e. Hasil untuk Peralatan dan Ruangan dalam Kuesioner Fasilitas pendukung didapatkan bahwa interpretasi skor hasil pengamatan semuanya bernilai 100\% dan di gambar 8 masuk dalam interval Sangat Baik yang berarti Peralatan dan ruangan tersebut dinilai sangat Baik oleh 18 Responden. Sedangkan untuk konsumsi interpretasi skor hasil pengamatan bernilai 95,556\% dan di gambar 8 masuk dalam interval Sangat Baik yang berarti Konsumsi tersebut dinilai sangat Baik oleh 18 Responden.

f. Hasil kuesioner didapatkan saran terbanyak untuk selanjutnya agar diadakan pelatihan adalah Kerajinan tangan, masukan lainnya agar kegiatan pelatihan berlanjut.

g. Hasil monitoring didapatkan bahwa terdapat warga yang telah membuat pempek dan berjualan di lingkungan pasir panjang.

\section{UCAPAN TERIMA KASIH}

Ucapan Terima kasih disampaikan kepada Civitas Academika Jurusan Informatika Polibatam sebagai pelaksana kegiatan, RW. 3 Kelurahan Pasir Panjang Kecamatan Rempang Cate sebagai tuan rumah dan semua pihak yang telah berkontribusi terhadap pelaksanaan pengabdian, Pengabdian ini didanai oleh Pusat Penelitian dan Pengabdian Masyarakat Polibatam.

\section{DAFTAR PUSTAKA}

Pemerintah Provinsi Kepulauan Riau. (2016). Rancangan Akhir Rencana Pembangunan Jangka Menengah Daerah (RPJMD) 2016 - 2021.

Afiatin, T., Sonjaya, J. A., \& Pertiwi, Y. G. (2013). Mudah dan Sukses Menyelenggarakan Pelatihan: Melejitkan Potensi Diri. Yogyakarta, Indonesia: Kanisius.

Gustin, O., Sukojo, B. M., \& Handayani, H. H. (2013). Perbandingan Algoritma Suhu Permukaan Tanah (SPT) dan Indeks Vegetasi (IV) pada Satelit Landsat Daerah Jawa Timur. Prosiding Seminar Nasional Aplikasi Teknologi Prasarana Wilayah (ATPW), 26 Juni 2013. 
Surabaya, Indonesia: Program Diploma Teknik Sipil Fakultas Teknik Sipil dan Perencanaan Institut Teknologi Sepuluh Nopember Surabaya. D-23.

Gustin, O. (2016). Determining The Best Coral Reef habitat in Coastal Island of Batam. Proceeding The 1st Geomatics International Conference (GEOICON). Surabaya, Indonesia: Jurusan Teknik Geomatika Fakultas Teknik Sipil dan Perencanaan Institut Teknologi Sepuluh Nopember Surabaya.

Gustin, O., Roziqin, A., \& Kurniawan, D. E. (2017). Detection of Land Use Changes in Batam Island Coastal Using Remote Sensing. Proceeding ITS International Geoscience Convention, Institut Teknologi Sepuluh Nopember Surabaya.

Gustin, O., Roziqin, A., \& Fatulloh A. (2018). Determination and Measurement of Horizontal Control Points 2nd Order. 2018 International Conference on Applied Engineering (ICAE), 1-5. doi: 10.1109/INCAE.2018.8579379.

Likert, R. A. (1932). Technique for the measurement of attitudes. Archives of Psychology, 140 pp: $1-55$

Roziqin, A., Gustin, O., \& Syari, I.P. (2018). Landslide Distribution Using Geographic Information System in Batam Island. 2018 International Conference on Applied Engineering (ICAE), 1-5. doi: 10.1109/INCAE.2018.8579371.

\section{DAFTAR LAMAN}

Bnpbpadang. (13, Februari 2019). Pempek, Makanan Tradisional Khas Palembang. Diakses dari http://kebudayaan.kemdikbud.go.id/bpnbsumbar/pempek-makanan-tradisional-khaspalembang/. 